\title{
Role of MRI-based radiomics in locally advanced rectal cancer (Review)
}

\author{
SIYU ZHANG ${ }^{1 *}$, MINGRONG YU $^{2 *}$, DAN CHEN $^{1}$, PEIDONG $^{3}{ }^{3}$, BIN TANG $^{4}$ and $\mathrm{JIE} \mathrm{LI}^{4}$ \\ ${ }^{1}$ School of Medicine, University of Electronic Science and Technology of China, Chengdu, Sichuan 610041; \\ ${ }^{2}$ College of Physical Education, Sichuan Agricultural University, Ya'an, Sichuan 625000; ${ }^{3}$ Second Department of \\ Gastrointestinal Surgery, The Affiliated Hospital of North Sichuan Medical College, Nanchong, Sichuan 637000; \\ ${ }^{4}$ Sichuan Cancer Hospital and Institute, Sichuan Cancer Center, School of Medicine, University of Electronic Science and \\ Technology of China, Radiation Oncology Key Laboratory of Sichuan Province, Chengdu, Sichuan 610041, P.R. China
}

Received September 27, 2021; Accepted November 29, 2021

DOI: 10.3892/or.2021.8245

\begin{abstract}
Colorectal cancer is the third most common type of cancer, with high morbidity and mortality rates. In particular, locally advanced rectal cancer (LARC) is difficult to treat and has a high recurrence rate. Neoadjuvant chemoradiotherapy (NCRT) is one of the standard treatment programs of LARC. If the response to treatment and prognosis in patients with LARC can be predicted, it will guide clinical decision-making. Radiomics is characterized by the extraction of high-dimensional quantitative features from medical imaging data, followed by data analysis and model construction, which can be used for tumor diagnosis, staging, prediction of treatment response and prognosis. In recent years, a number of studies have assessed the role of radiomics in NCRT for LARC. MRI-based radiomics provides valuable data and is expected to become an imaging biomarker for predicting treatment response and prognosis. The potential of radiomics to guide personalized medicine is widely recognized; however, current limitations and challenges prevent its application to clinical decision-making. The present review summarizes
\end{abstract}

Correspondence to: Professor $\mathrm{Jie} \mathrm{Li}$ or Professor Bin Tang, Sichuan Cancer Hospital and Institute, Sichuan Cancer Center, School of Medicine, University of Electronic Science and Technology of China, Radiation Oncology Key Laboratory of Sichuan Province, 55 Section 4 South Renmin Road, Wuhou, Chengdu, Sichuan 610041, P.R. China

E-mail: jie.li@yeah.net

E-mail: jackytang86@163.com

*Contributed equally

Abbreviations: LARC, locally advanced rectal cancer; NCRT, neoadjuvant chemoradiotherapy; PET, positron emission tomography; TME, total mesorectal excision; T1WI, T1-weighted imaging; T2WI, T2-weighted imaging; PCR, pathological complete response

Key words: LARC, radiomics, NCRT, MRI, imaging biomarkers the applications, limitations and prospects of MRI-based radiomics in LARC.

\section{Contents}

1. Introduction

2. Process of radiomics

3. Application of MRI radiomics in NCRT of LARC

4. Challenges and prospects

5. Conclusion

\section{Introduction}

Colorectal cancer is the third most common type of cancer in the world and the second leading cause of cancer-associated death in the United States $(1,2)$. According to the global cancer statistics in 2020 , there were $>1.9$ million new cases of colorectal cancer, among which rectal cancer accounted for $30-50 \%$, and 935,000 associated deaths $(3,4)$. Approximately half of rectal cancer diagnoses are of locally advanced rectal cancer (LARC), which is difficult to treat and has a poor prognosis (5). According to the Tumor-Node-Metastasis classification (6,7), LARC is defined as patients with cT3-cT4 or $\mathrm{N}^{+}$(stage II or III) rectal cancer without distant metastasis (8). Neoadjuvant chemoradiotherapy (NCRT) followed by total mesorectal excision (TME) after 6-10 weeks is the preferred treatment for $\operatorname{LARC}(9,10)$. NCRT can decrease the tumor size and tumor stage, block tumor invasion, and improve resection during surgery and the probability of sphincter preservation, thus increasing the local control rate and the survival rate of the patient (10-13).

Identifying biomarkers that predict the response to NCRT is a constant challenge. Numerous studies have proposed biomarkers that could predict response to NCRT in patients with LARC, such as tumor stage, tumor regression grade, tumor markers (carcinoembryonic antigen), circulating tumor-derived DNA, DNA methylation level and cancer related-inflammatory markers; however, their accuracy is not perfect (14-17). As LARC has great heterogeneity in 
proteins, genes, cells and tissues (18), it is difficult to capture its heterogeneity by using examinations such as pathological biopsy, colonoscopy and hematology (19-21). By contrast, as a new non-invasive imaging technology, radiomics transforms medical imaging into high-dimensional data that can be mined to reveal a large number of quantitative features, including texture, grayscales, wavelet and fractal, and combines quantitative features with clinical features, protein genome information and other information $(22,23)$. With its advantages, such as being easy to operate, a low cost and a high efficiency in capturing the heterogeneity of tumors, it can be used for tumor diagnosis, staging, prognosis and predicting treatment response (24-27); it also has great potential to be an imaging biomarker for predicting the response to NCRT and determining the prognosis.

In recent years, there has been an increase in the amount of research into MRI-based radiomics in LARC. In the present review, based on existing research, the workflow of radiomics will first be introduced, and then the research into MRI-based radiomics for predicting the response of patients with LARC to NCRT, and their prognosis, will be summarized. Lastly, the challenges and development trends of MRI-based radiomics will be discussed.

\section{Process of radiomics}

Radiomics generally includes the following steps (Fig. 1): i) Obtaining medical imaging data is the first step of radiomics. The accuracy and repeatability of the radiomics model are associated with the quality of the images. ii) Image segmentation to obtain the region of interest (ROI). This is a key and challenging step, and subsequent feature extraction is taken from this region. The acquired images differ due to different scanning models and parameters; therefore, it is necessary to standardize the images before acquiring the ROI. The ROI segmentation can be divided into three types: Manual, semi-automatic and automatic. Manual segmentation is considered the gold standard. However, it is relatively time-consuming, cumbersome and susceptible to operator variability $(28,29)$. iii) Selecting and extracting features. Radiomics features can be roughly divided into four categories: Size and shape features, first-order statistical, second-order statistical and change-based features, such as intensity, shape, texture and wavelet features. The most common feature is texture. Feature selection and extraction is a process of data dimension reduction, and can be divided into supervised dimension reduction [such as least absolute shrinkage and selection operator (LASSO), linear discriminate analysis] and unsupervised dimension reduction (such as principal component analysis and cluster analysis) (30-32). iv) Analysis (establishing models). Establishing a practical and accurate model to predict clinical outcomes is the ultimate goal of radiomics. Commonly used models include Cox proportional hazard regression, logistic regression, LASSO, random forest algorithm and support vector machine (22,33-35). It is worth noting that in the actual modeling process, it is often necessary to use a variety of modeling methods to avoid the shortcomings of different modeling methods in order to establish a more accurate radiomics model (26). v) Model application (classification and prediction). This can be used for tumor diagnosis, staging, prognosis and predicting treatment response.

\section{Application of MRI radiomics in NCRT of LARC}

Imaging examination is an important medical technique, which is mainly used to assist clinical decision-making in clinical practice (36). With the rapid development of medical technology, imaging examination has gradually evolved from a clinical diagnostic tool to a powerful tool for personalized medicine (37). The most common imaging examinations for the diagnosis and staging of rectal cancer include CT, MRI, positron emission tomography (PET)/CT and ultrasound endoscopy (38). CT is able to show the structural characteristics of tumors, and is often used in dosimetry research and tumor staging of rectal cancer radiotherapy (39). However, it also has some shortcomings, such as the inability to describe the function of solid tumors, limited $\mathrm{T}$ staging of early rectal cancer, high radiation and low contrast $(40,41)$. PET/CT is mainly used to evaluate the metabolic activity of tumors, which are usually more active than normal tissue (42). In addition, it is used for tumor diagnosis, staging and assessment of metastasis in rectal cancer; however, its spatial resolution is low, thus tumor T staging is limited. At the same time, $\mathrm{PET} / \mathrm{CT}$ not only has a high price, high radiation toxicity and relatively complicated usability, but it is also difficult to describe and analyze the features of its lesions in radiomics research $(40,43)$. By contrast, MRI has high resolution for soft tissue, and has the advantages of being radiation-free, multi-orientational, multi-parameter and delineating the tumor boundary clearly $(44,45)$. MRI is considered as the standard for the evaluation and staging of rectal cancer, and has wide application value in LARC $(38,46,47)$. In recent years, the research into radiomics in rectal cancer has increased year on year, and there is more research into radiomics-based on MRI than that based on CT or PET/CT. This indicates that radiomics-based on MRI is of great research significance and has potential in rectal cancer (Fig. 2). MRI has multi-parameter characteristics, which can be divided into morphological and functional parameters. Morphological parameters include T1-weighted imaging (T1WI) and T2-weighted imaging (T2WI), while functional parameters include diffusion-weighted imaging and enhanced scanning. The most commonly used examination parameter (sequence) is T2WI, with an accuracy of $65-94 \%$ for T staging and $35-75 \%$ for $\mathrm{N}$ staging in rectal cancer $(32,48)$ (Fig. 3). Morphological imaging is beneficial to provide detailed information of rectal cancer and its surrounding structures. Functional imaging distinguishes residual tumors from fibrosis (49). The information provided by the various imaging methods is different. Combining different imaging features can improve the prediction efficiency of the model. MRI radiomics, as an imaging biomarker, can predict the response of patients with rectal cancer to NCRT and the prognosis of the tumor from numerous aspects, including pathological complete response (PCR) determination, lymph node status, KRAS status, tumor-stroma ratio and tumor heterogeneity (31,50-52). The following is an analysis from the three aspects: PCR determination, lymph node status and KRAS status (Table I). Data for the present study, including Table I, was obtained by searching 


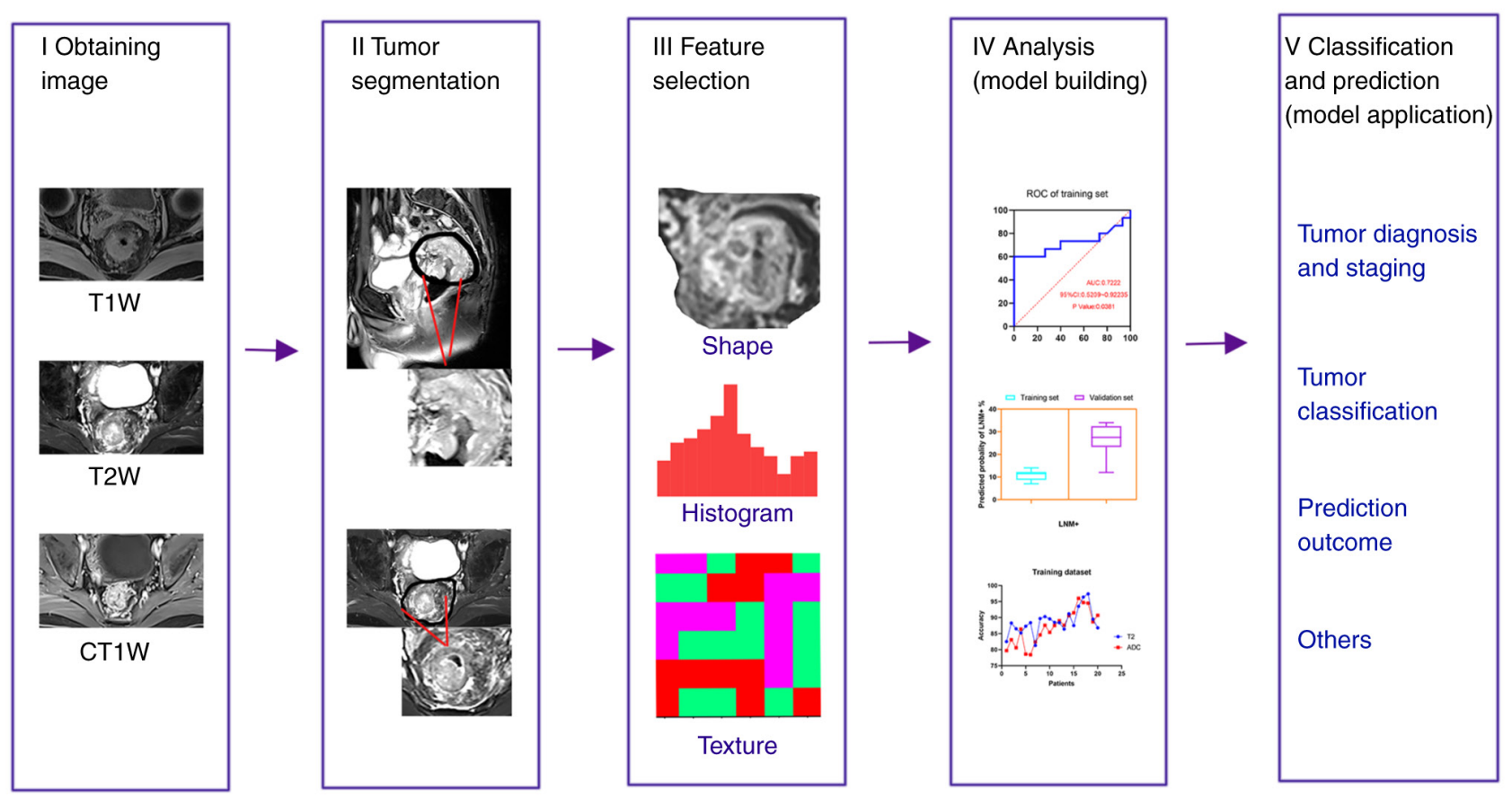

Figure 1. Radiomics workflow. (i) Obtaining medical imaging data; (ii) image segmentation to obtain the region of interest; (iii) selecting and extracting features; (iv) statistical analysis and model building; (v) classification and prediction. T1W, T1-weighted; CT1W, contrast enhanced T1-weighted images.

the Pubmed (http://www.ncbi.nlm.nih.gov), WebofScience (http://www.webofscience.com) and Metstroge (https://www. metstr.com) databases from mainly the last 6 years (with a few studies prior to 2015). The key words used include radiomics and locally advanced rectal cancer rectal cancer, NCRT, MRI, CT, PET, PCR, lymph nodes, Kras, challenges, limitations and prospects. Approximately $>300$ studies were searched, and $>100$ studies were finally cited.

MRI-based radiomics to predict PCR. The curative effect of NCRT on LARC is notable; however, the individual response to treatment varies, from a PCR to almost no tumor regression, while some patients have tumor progression (53). In total, $20 \%$ of the patients can attain a PCR (54), and a PCR is equivalent to no residual tumor cells (55-57). Patients with a PCR are able to receive 'waiting or watching' treatment, which is a non-surgical treatment strategy used for patients to obtain complete clinical remission $(58,59)$. If PCR can be predicted prior to surgery, personalized medicine can be used. A large number of studies have shown that MRI radiomics is effective in predicting the tumor response of LARC following NCRT. Yi et al (50) used T2WI radiomics, combining imaging features with clinical pathological characteristics to construct a prediction model. The results showed good diagnostic accuracy in predicting a PCR, a good response and tumor degradation in patients with LARC who had progressed to NCRT, and the area under curve values were 0.908, 0.902 and 0.930 , respectively. Dinapoli et al (60) analyzed the radiomics of 221 patients from three different centers and concluded that the MRI radiomics model could predict the probability of a PCR in patients with LARC using pre-treatment imaging. The study also established external verification (performed with patients from two other institutions) to further improve the credibility of its model. In addition, Li et al (61) completed
MRI prior to and following NCRT, and analyzed the images in parallel. By comparing the changes in the images during treatment, seven radiomics features were extracted. The prediction model could effectively predict a PCR following NCRT. It could be concluded that MRI prior to and following NCRT is an important source of radiomics data. At the same time, the radiomics model also predicted patients who were unresponsive or low in response to treatment. This was beneficial as the treatment plan could be adjusted in clinical practice, unnecessary toxicity of radiotherapy and chemotherapy could be avoided, and the economic burden for the patients could be reduced. Zhou et al (62) analyzed the multi-parameter MRI in 425 patients with LARC prior to NCRT. It was concluded that the features of multi-parameter MRI prior to treatment could effectively predict patients who were non-response to NCRT. Therefore, MRI-based radiomics, whether multi-parameter or single-sequence MRI radiomics, is of great significance in evaluating PCR and unresponsiveness following NCRT. This could provide an improved basis for personalized treatment.

MRI-based radiomics to predict lymph node status. Most treatment responses following NCRT are evaluated by observing the primary tumor; however, lymph nodes can also be evaluated, as NCRT can cause heterogeneous response of the lymph nodes (63). NCRT can cause certain changes in the lymph nodes, such as changes in their morphology, size, number and texture. In addition, the response of the lymph nodes to NCRT varies, ranging from a large number of residual cancer cells to a completely fibrotic response (the surrounding normal cells continue to proliferate to repair the damage caused by radiotherapy and chemotherapy, which specifically means that there are no residual tumor cells). Therefore, it can be complicated to interpret the prognostic impact of the lymph nodes following NCRT due to the changes in the lymph nodes (64). A large 


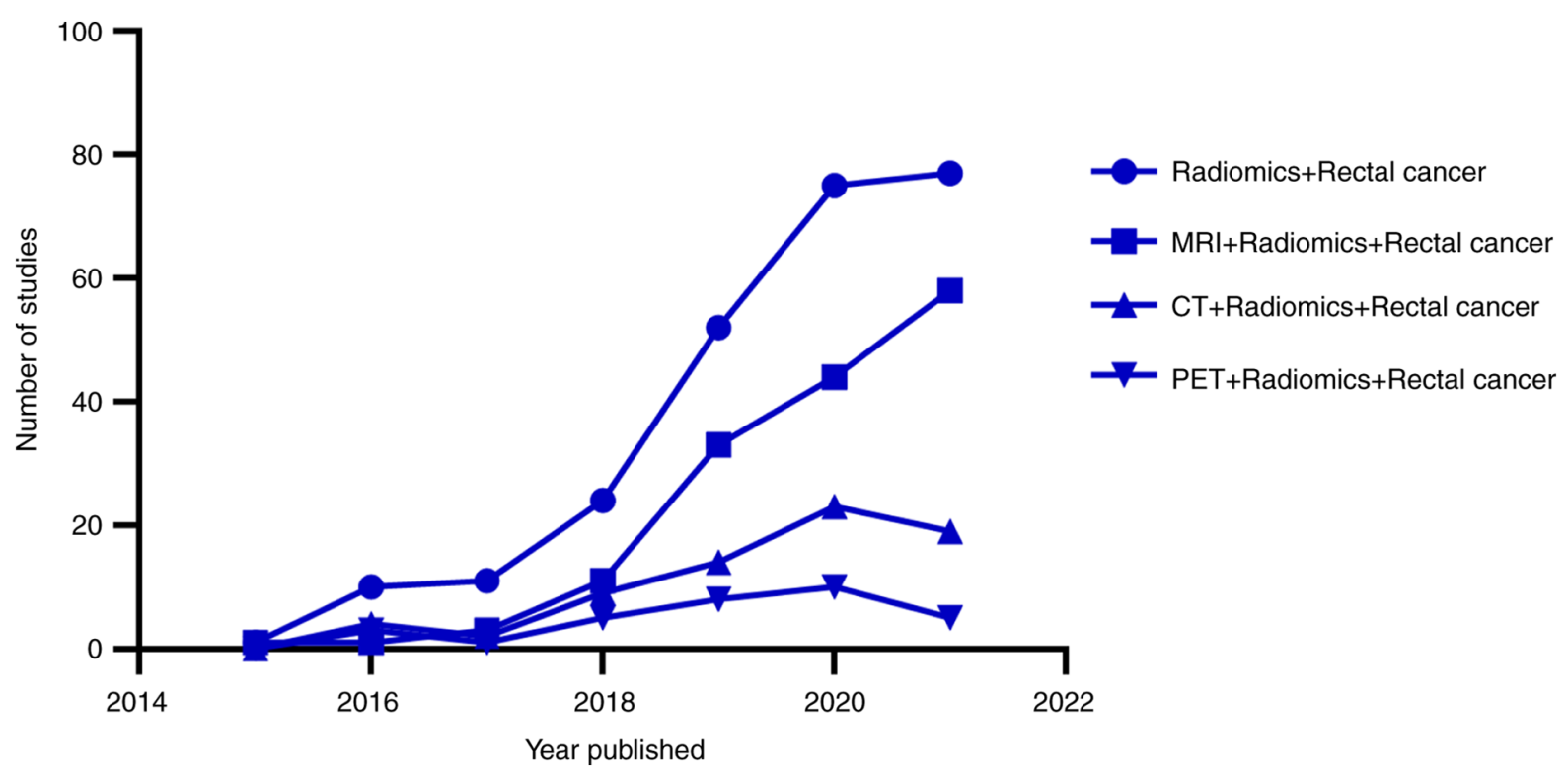

Figure 2. Comparison of radiomics studies into rectal cancer in different imaging modalities (based on the Web of Science database). MRI radiomics studies were significantly higher in number compared with the CT/PET radiomics studies. PET, positron emission tomography. The data were obtained by searching the Web of Science and Pubmed databases, according to the search terms 'Radiomics + Rectal cancer', 'MRI + Radiomics + Rectal cancer', 'CT + Radiomics + Rectal cancer' and 'PET + Radiomics + Rectal cancer'. The literature retrieved was skimmed and compared, and then the qualified literature was included (the data may be incomplete, so are only for reference).
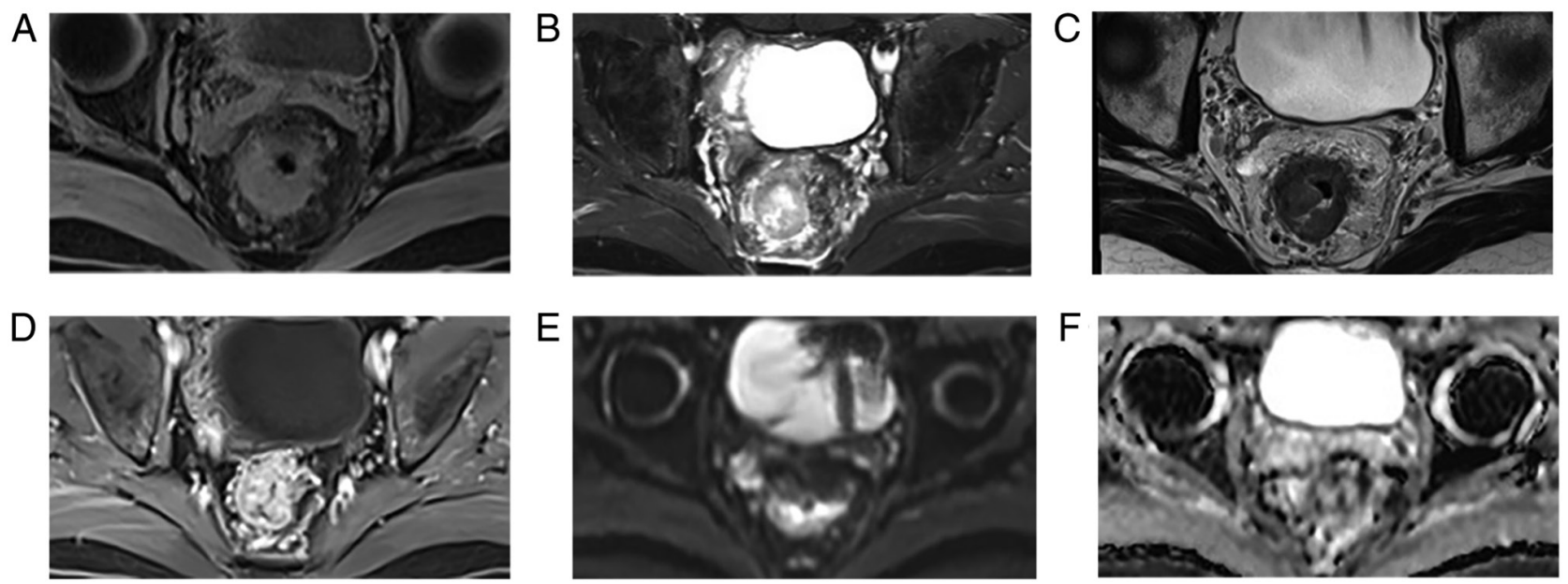

Figure 3. Comparison of different MRI sequences in a patient with locally advanced rectal cancer. Different images from a patient with cT4N1M0 rectal cancer using MRI, including (A) T1WI, (B) T2WI, (C) T2 high-resolution sequence, (D) contrast-enhanced T1WI, (E) diffusion-weighted imaging and (F) apparent diffusion coefficient. T1WI, T1-weighted imaging; T2WI, T2-weighted imaging.

number of previous studies have shown that the positive mesenteric lymph nodes are the main cause of the local recurrence and distant spread of rectal cancer (51,65-67). TME is significantly effective for local tumor control; however, there are numerous complications, such as sexual dysfunction, poor urination and infection (68-70). Therefore, organ preservation strategies, such as watchful waiting and local excision following NCRT, are particularly important in preserving organ function and improving the quality of life of the patients $(71,72)$. It is worth noting that the status of the lymph nodes following NCRT is an important indicator of organ preservation strategies $(63,73)$. Hence, assessing the status of the lymph nodes following NCRT is of great significance in assessing treatment response, predicting prognosis and improving the quality of life of patients.
In the past, clinicians often used the size of the lymph nodes to estimate which lymph nodes could have metastases and which could be free of metastatic foci (74), to assess the volume reduction rate prior to and following treatment to evaluate lymph node metastasis (75), or to predict the status of the lymph nodes using clinicopathological factors (76); however, precise prediction accuracy has not been achieved. In recent years, with the development of artificial intelligence and big data, radiomics studies have become increasingly popular in the clinic. A large number of studies have shown that radiomics can effectively predict the status of the lymph nodes and provide a basis for clinical decision-making. For example, Zhou et al (72) predicted the status of the lymph nodes following NCRT using a multi-parameter MRI 
Table I. Summary of the application of MRI radiomics in locally advanced rectal cancer.

\begin{tabular}{|c|c|c|c|c|c|c|c|}
\hline First author, year & $\begin{array}{l}\text { Image } \\
\text { modality }\end{array}$ & Study design & $\begin{array}{l}\text { Feature } \\
\text { type }\end{array}$ & $\begin{array}{l}\text { Statistical } \\
\text { method }\end{array}$ & $\begin{array}{l}\text { Feature } \\
\text { selection } \\
\text { model }\end{array}$ & Clinical utility & (Refs.) \\
\hline Bulens et al, 2020 & $\begin{array}{l}\text { T2WI, DWI, } \\
\text { ADC }\end{array}$ & $\begin{array}{l}\text { Retrospective } \\
\text { single-center }\end{array}$ & Semantic & $\begin{array}{l}\text { Multivariate } \\
\text { analysis }\end{array}$ & LASSO & Prediction PCR & (30) \\
\hline Zhang et al, 2021 & $\mathrm{~T} 2 \mathrm{WI}$ & $\begin{array}{l}\text { Retrospective } \\
\text { single-center }\end{array}$ & Texture & $\begin{array}{l}\text { Multivariate } \\
\text { analysis }\end{array}$ & LASSO & $\begin{array}{l}\text { Prediction } \\
\text { KRAS }\end{array}$ & (31) \\
\hline Petresc et al, 2020 & T2WI & $\begin{array}{l}\text { Retrospective } \\
\text { single-center }\end{array}$ & $\begin{array}{l}\text { Wavelet, } \\
\text { texture }\end{array}$ & $\begin{array}{l}\text { Univariate } \\
\text { analysis }\end{array}$ & LASSO & $\begin{array}{l}\text { Prediction } \\
\text { NRs }\end{array}$ & $(32)$ \\
\hline Yi et al, 2019 & $\begin{array}{l}\text { T2WI, T1WI, } \\
\text { cT1W }\end{array}$ & $\begin{array}{l}\text { Retrospective } \\
\text { single-center }\end{array}$ & Texture & $\begin{array}{l}\text { Univariate } \\
\text { analysis }\end{array}$ & $\begin{array}{l}\text { LASSO, } \\
\text { RF, SVM }\end{array}$ & $\begin{array}{l}\text { Prediction PCR, } \\
\text { GR, downstaging }\end{array}$ & $(50)$ \\
\hline Cai et al, 2021 & $\begin{array}{l}\text { T2WI, } \\
\text { DWI, cT1W, } \\
\text { ADC }\end{array}$ & $\begin{array}{l}\text { Retrospective } \\
\text { single-center }\end{array}$ & $\begin{array}{l}\text { Shape, } \\
\text { texture, } \\
\text { wavelet }\end{array}$ & $\begin{array}{l}\text { Univariate } \\
\text { analysis }\end{array}$ & $\begin{array}{l}\text { LASSO, } \\
\text { logistic } \\
\text { regression }\end{array}$ & Prediction TSR & $(52)$ \\
\hline De Cecco et al, 2015 & $\mathrm{~T} 2 \mathrm{WI}$ & $\begin{array}{l}\text { Prospective } \\
\text { single-center }\end{array}$ & Texture & $\begin{array}{l}\text { Multivariate } \\
\text { analysis }\end{array}$ & $\begin{array}{l}\text { Mann-Whitney } \\
\text { U test }\end{array}$ & $\begin{array}{l}\text { Prediction PCR, } \\
\text { PR, NRs }\end{array}$ & $(53)$ \\
\hline Cui et al, 2021 & $\begin{array}{l}\text { T2WI, } \\
\text { T1WI, ADC }\end{array}$ & $\begin{array}{l}\text { Retrospective } \\
\text { single-center }\end{array}$ & $\begin{array}{l}\text { First-order } \\
\text { statistical, } \\
\text { shape, } \\
\text { texture }\end{array}$ & $\begin{array}{l}\text { Multivariate } \\
\text { analysis }\end{array}$ & $\begin{array}{l}\text { Boruta } \\
\text { algorithm, RF }\end{array}$ & Prediction DFS & $(54)$ \\
\hline Li et al, 2019 & T2WI, T1WI & $\begin{array}{l}\text { Retrospective } \\
\text { single-center }\end{array}$ & Texture & $\begin{array}{l}\text { Multivariate } \\
\text { analysis }\end{array}$ & $\begin{array}{l}\text { Logistic } \\
\text { regression }\end{array}$ & Prediction PCR & $(61)$ \\
\hline Zhou et al, 2019 & $\begin{array}{l}\text { T2WI, T1WI, } \\
\text { cT1W, DWI }\end{array}$ & $\begin{array}{l}\text { Retrospective } \\
\text { single-center }\end{array}$ & Texture & $\begin{array}{l}\text { Univariate, } \\
\text { multivariate } \\
\text { analysis }\end{array}$ & LASSO & Prediction NRs & $(62)$ \\
\hline Zhou et al, 2020 & $\begin{array}{l}\text { T2WI, T1WI, } \\
\text { DWI, } \\
\text { CE-T1w }\end{array}$ & $\begin{array}{l}\text { Retrospective } \\
\text { single-center }\end{array}$ & $\begin{array}{l}\text { Texture, } \\
\text { LoG } \\
\text { filtration }\end{array}$ & $\begin{array}{l}\text { Wilcoxon } \\
\text { rank-sum }\end{array}$ & $\begin{array}{l}\text { LASSO, } \\
\text { logistic } \\
\text { regression }\end{array}$ & $\begin{array}{l}\text { Prediction } \\
\text { lymph node } \\
\text { status }\end{array}$ & $(72)$ \\
\hline Song et al, 2020 & $\mathrm{~T} 2 \mathrm{WI}$ & $\begin{array}{l}\text { Retrospective } \\
\text { single-center }\end{array}$ & Texture & $\begin{array}{l}\text { Univariate, } \\
\text { multivariate } \\
\text { analysis }\end{array}$ & $\begin{array}{l}\text { Logistic } \\
\text { regression }\end{array}$ & $\begin{array}{l}\text { Prediction } \\
\text { lymph node } \\
\text { status }\end{array}$ & (77) \\
\hline Oh et al, 2020 & T2WI & $\begin{array}{l}\text { Retrospective } \\
\text { single-center }\end{array}$ & Texture & $\begin{array}{l}\text { Univariate } \\
\text { analysis }\end{array}$ & Decision tree & $\begin{array}{l}\text { Prediction } \\
\text { KRAS }\end{array}$ & $(91)$ \\
\hline Li et al, 2020 & $\begin{array}{l}\text { CT MRI } \\
\text { (DCE-T1w, } \\
\text { T2WI, ADC) }\end{array}$ & $\begin{array}{l}\text { Retrospective } \\
\text { single-center }\end{array}$ & $\begin{array}{l}\text { Texture, } \\
\text { morpho } \\
\text { logical }\end{array}$ & $\begin{array}{l}\text { Multivariate } \\
\text { analysis }\end{array}$ & LASSO & $\begin{array}{l}\text { Prediction } \\
\text { treatment } \\
\text { response }\end{array}$ & (97) \\
\hline Giannini et al, 2019 & $\begin{array}{l}\text { PET MRI } \\
(T 2 W I, D W I, \\
\text { ADC) }\end{array}$ & $\begin{array}{l}\text { Retrospective } \\
\text { single-center }\end{array}$ & $\begin{array}{l}\text { First- } \\
\text { order } \\
\text { statistical, } \\
\text { texture }\end{array}$ & $\begin{array}{l}\text { Univariate, } \\
\text { multivariate } \\
\text { analysis }\end{array}$ & $\begin{array}{l}\text { Mann-Whitney } \\
\text { test }\end{array}$ & $\begin{array}{l}\text { Prediction } \\
\text { treatment } \\
\text { response }\end{array}$ & $(98)$ \\
\hline Cui et al, 2021 & $\begin{array}{l}\text { T2WI, cT1W, } \\
\text { ADC }\end{array}$ & $\begin{array}{l}\text { Prospective } \\
\text { single-cente }\end{array}$ & Texture & $\begin{array}{l}\text { Multivariate } \\
\text { analysis }\end{array}$ & $\begin{array}{l}\mathrm{RF}, \mathrm{Cox} \\
\text { regression }\end{array}$ & $\begin{array}{l}\text { Prediction } \\
\text { survival time }\end{array}$ & $(54)$ \\
\hline Cui et al, 2019 & $\begin{array}{l}\text { T2WI, DWI, } \\
\text { cT1W, ADC }\end{array}$ & $\begin{array}{l}\text { Retrospective } \\
\text { single-center }\end{array}$ & Texture & $\begin{array}{l}\text { Multivariate } \\
\text { analysis }\end{array}$ & LASSO & Prediction PCR & (99) \\
\hline
\end{tabular}

T2WI, T2-weighted imaging; T1WI, T1-weighted imaging; CT1W, contrast-enhanced T1-weighted images; DWI, diffusion-weighted imaging; CE-T1w, contrast-enhanced T1-weighted fast spin-echo imaging; ADC, apparent diffusion coefficient; LASSO, left absolute shrinkage and selection operator; RF, random forest; SVM, support vector machine; PCR, pathological complete response; GR, good response; NRs, non-response; TSR, tumor-stroma ratio; LOG, Laplacian of Gaussian; DFS, disease-free survival.

radiomics model. The joint model of multi-parameter MRI radiomics features and tumor staging was obtained. The receiver operating characteristic curve was 0.818 and the negative predictive value was $93.7 \%$ in the validation cohort, 
which was higher than that in the single imaging model. In particular, the combined model had high accuracy in evaluating the lymph node status in patients with MRI T1-2 tumors following NCRT, and its negative predictive value was as high as $100 \%$. Song and Yin (77) found that the low energy of sagittal fat inhibition T2WI, and the high information correlation and short-run low gray-level emphasis of oblique T2WI, were independent predictors of lymph node invasion of rectal cancer. These have a certain value in judging preoperative lymph node invasion.

In summary, MRI-based radiomics has the advantage of being non-invasive and easy to use, with a high prediction accuracy and no need to visualize features (tumor shape, edge and size). MRI also has a good ability to identify lymph nodes, which has great potential in predicting the lymph node status of patients with LARC following NCRT. However, there are relatively few studies based on this aspect at present, which requires the support of big data and multi-center research. This presents an opportunity for future scientific research.

MRI-based radiomics to predict KRAS mutation. A large number of studies have reported that the KRAS mutation is a good biomarker to predict the resistance and prognosis of metastatic rectal cancer with anti-epidermal growth factor receptor monoclonal antibody therapy $(78,79)$. The KRAS gene is a murine sarcomatoid virus oncogene that belongs to the RAS gene family and has been associated with the development of human tumors. The KRAS mutation is the most common gene mutation in colorectal cancer. Between 30 and $40 \%$ of patients with colorectal cancer carry the KRAS mutation (80). In LARC, the KRAS mutation has been associated with tumor invasion and metastasis, insensitivity to epidermal growth factor inhibitor and low overall survival time $(81,82)$. Certain patients with LARC have low sensitivity to NCRT, and have side effects to radiotherapy and chemotherapy, such as trisomy, radiation proctitis and sexual dysfunction. Early in vitro experiments have proved that cell lines with the KRAS mutation are more prone to radiation resistance and mediate the radiation resistance of cells via the EGFR/PI3K/AKT pathway $(83,84)$. At present, there are numerous studies investigating the association between the KRAS mutation and treatment response following NCRT. For example, Zhou et al (82) retrospectively analyzed 1,886 patients with LARC, and found that the KRAS mutation was not associated with low PCR rate and tumor degradation following neoadjuvant treatment of LARC; however, the KRAS mutation was associated with low survival rate following NCRT, suggesting a poor prognosis. In another study, Peng et al (85) retrospectively analyzed 70 patients with LARC who received NCRT prior to surgery at the Cancer Center of Sun Yat-Sen University (Guangzhou, China). It was concluded that the 3-year disease-free survival rate and the 3-year overall survival rate were lower in patients with the KRAS mutation gene than in patients who did not have the mutation. In addition, the response to preoperative radiotherapy and chemotherapy was worse in patients with the KRAS mutation compared with that in patients who did not have the mutation. Therefore, the detection of the KRAS mutation is of great importance for clinicians to predict the response to NCRT and determine the prognosis.
At present, the methods for detecting the KRAS mutation are mainly based on tumor biopsy specimens or surgical resection specimens, and are performed following surgery. This has several disadvantages, including invasiveness, complexity and high cost, and the quality of the specimens may not be guaranteed. If the gene mutation could be detected by radiomics prior to surgery, it would save on medical resources, relieve the distress of the patients and more importantly, provide effective prognostic indicators. Different molecular subtypes of rectal cancer often have different morphological features (86). In recent years, various MRI sequences (i.e. diffusion-weighted MRI, routine MRI, dynamic contrast-enhanced MRI and MR spectroscopy) have been used to evaluate the biological characteristics of the tumor and predict KRAS status (87-89). In particular, radiomics analysis based on MRI has become a hot topic, as it is a non-invasive method and can be used to evaluate the heterogeneity within the tumor, which is difficult to determine using the naked eye (90). Zhang et al (31) established a radiomics model using MRI prior to NCRT and extracted the image feature X.LL_scaled_std, which has high predictive performance in predicting the KRAS mutation prior to NCRT in patients with LARC. Similarly, Oh et al (91) also confirmed that T2WI radiomics has high predictive performance for preoperative KRAS status of rectal cancer. Therefore, MRI-based radiomics features could effectively predict KRAS mutation prior to NCRT in patients with LARC, and could be used to evaluate treatment response and determine prognosis. However, this still requires further verification using a large multicenter cohort and prospective trials. If applied to clinical decision-making, it will avoid the side effects of radiotherapy and chemotherapy, and provide a non-invasive treatment for targeted therapy.

\section{Challenges and prospects}

Current research provides clinical prospects regarding radiomics; however, there are still certain shortcomings. Firstly, due to the complexity of establishing the workflow of radiomics, the image acquisition and protocols of the different institutions vary. In addition, there are also differences among various scanning instruments, including in the standardization of the signal intensity and how the image data should be shared from different medical institutions, which requires resolving. Secondly, most radiomics features are extracted from the maximum cross-sectional area of the tumor, rather than the whole tumor. This information may not be representative of all the tumor information. Thirdly, the ROI is mainly determined manually, which is time-consuming and laborious, and depends on the experience of the examiner, resulting in the reduction of repeatability. Fourthly, a large number of radiomics models have poor reproducibility, are mostly retrospective studies and lack independent external verification. Finally, there is still a lack of large sample, multi-center and prospective studies $(26,50,92-96)$.

If the aforementioned problems can be solved, it will lay a solid foundation for the realization of personalized medicine. Until now, most studies have only used single-modality imaging methods, such as CT, MRI and PET. It has been reported that a multi-modality radiomics model has higher prediction efficiency compared with that for a single-modality 
radiomics model. Li et al (97) combined the two imaging modalities of CT and MRI to establish a radiomics model, while comparing it with separate CT or MRI models. It was concluded that the multi-modality radiomics model was more accurate in predicting the treatment response to NCRT. In another study combining ${ }^{18} \mathrm{~F}$-fluorodeoxyglucose PET and MRI radiomics, the combined model had higher predictive value in predicting the NCRT response in patients with LARC compared with that for the MRI model alone (98). There are also reports showing that the multi-parameter MRI radiomics model had higher accuracy compared with that of the single-sequence radiohistology model. In a study using a multi-parameter MRI (T1WI, T2WI, diffusion-weighted and contrast-enhanced T1WI) radiomics model, a multi-parameter prediction model and four single-sequence prediction models were established. It was concluded that the multi-parameter prediction model had more potential in predicting unresponsive patients following NCRT in patients with LARC (62). The studies by Cui et al $(54,99)$ also showed similar results. In addition, the multi-parameter MRI radiomics model had more potential in predicting the response to NCRT in patients with LARC. It has also been reported that a multi-regional radiomics model could improve the predictive effectiveness of the model. Liu et al (100) combined multi-regional (tumor and mesorectum) MRI radiomics features with clinical data to build a model, which effectively improved the rate of predicting lymph node metastasis in rectal cancer.

In recent years, a new artificial intelligence method, known as deep learning, has also emerged. Deep learning is a machine learning algorithm characterized by a neural network, which can be used in image classification, object detection, computer vision, speech recognition and natural language processing. Compared with radiomics, it does not require image segmentation and intermediate feature extraction (101). Deep learning has been applied to numerous aspects of medical image analysis, such as image acquisition, image rectification and image classification (102). In the future, if radiomics can be combined with deep learning or machine learning methods to build a higher performance model, they may create a new field of personalized imaging medicine (102-104). At the same time, if a powerful and easy to use software was developed to obtain the ROI of the tumor, and semi-automatic or even full-automatic segmentation could be used, it would also save on medical resources.

\section{Conclusion}

In summary, radiomics provides new ideas and valuable data for clinical practice. MRI-based radiomics can predict the response and prognosis in patients with LARC to NCRT using PCR determination, the lymph node status and the KRAS mutation status. However, there are still some limitations and challenges in its application in clinical practice. In the future, analyses from multi-parameter, multi-modality and multi-regional radiomics may lead to improvements in the results. Radiomics may also be combined with machine learning methods, such as deep learning, to improve the predictive value. With the development of technology and medicine, radiomics has great potential as an imaging biomarker for predicting treatment response and determining prognosis, and could be used to assist clinical decision-making.

\section{Acknowledgements}

Not applicable.

\section{Funding}

This study was supported by the Sichuan Science and Technology Program (grant no. 2021YFG0320 and 2020YJ0446).

\section{Availability of data and materials}

Not applicable.

\section{Authors' contributions}

BT and JL designed the study and revised the manuscript. SZ and MY performed the literature research, analyzed the data, and drafted and wrote the final version of the manuscript. DC and PL participated in the conception of the study. All the authors read and approved the final manuscript. Data authentication is not applicable.

\section{Ethics approval and consent to participate}

This study has been approved by the Ethics Committee of Sichuan Cancer Hospital (Chengdu, China; approval no. SCCHEC-02-2020-008).

\section{Patient consent for publication}

The MRI sequence shown in Figs. 1 and 3 were from two patients with rectal cancer, cT3N1M0 and cT4N1M0, respectively, who were treated in Sichuan Cancer Hospital. All MRI imaging data were collected with written informed patient consent for publication.

\section{Competing interests}

The authors declare that they have no competing interests.

\section{References}

1. Gabriel E, Ostapoff K, Attwood K, Al-Sukhni E, Boland P and Nurkin S: Disparities in the age-related rates of colorectal cancer in the United States. Am Surg 83: 640-647, 2017.

2. Glynne-Jones R, Wyrwicz L, Tiret E, Brown G, Rödel C, Cervantes A and Arnold D; ESMO Guidelines Committee: Rectal cancer: ESMO clinical practice guidelines for diagnosis, treatment and follow-up. Ann Oncol 28 (Suppl_4): iv22-iv40, 2017.

3. Siegel RL, Miller KD, Goding Sauer A, Fedewa SA, Butterly LF, Anderson JC, Cercek A, Smith RA and Jemal A: Colorectal cancer statistics, 2020. CA Cancer J Clin 70: 145-164, 2020.

4. Ferlay J, Colombet M, Soerjomataram I, Dyba T, Randi G, Bettio M, Gavin A, Visser O and Bray F: Cancer incidence and mortality patterns in Europe: Estimates for 40 countries and 25 major cancers in 2018. Eur J Cancer 103: 356-387, 2018.

5. Bigness A, Imanirad I, Sahin IH, Xie H, Frakes J, Hoffe S, Laskowitz D and Felder S: Locally advanced rectal adenocarcinoma: Treatment sequences, intensification, and rectal organ preservation. CA Cancer J Clin 71: 198-208, 2021. 
6. Wei J, Huang R, Guo S, Zhang X, Xi S, Wang Q, Chang H, Wang X, Xiao W, Zeng Z and Gao Y: ypTNM category combined with AJCC tumor regression grade for screening patients with the worst prognosis after neoadjuvant chemoradiation therapy for locally advanced rectal cancer. Cancer Manag Res 10: 5219-5225, 2018.

7. Edge SB and Compton CC: The American Joint Committee on Cancer: The 7th edition of the AJCC cancer staging manual and the future of TNM. Ann Surg Oncol 17: 1471-1474, 2010.

8. Cercek A, Roxburgh CSD, Strombom P, Smith JJ, Temple LKF, Nash GM, Guillem JG, Paty PB, Yaeger R, Stadler ZK, et al: Adoption of total neoadjuvant therapy for locally advanced rectal cancer. JAMA Oncol 4: e180071, 2018.

9. Conroy T, Bosset JF, Etienne PL, Rio E, François É, Mesgouez-Nebout N, Vendrely V, Artignan X, Bouché O, Gargot D, et al: Neoadjuvant chemotherapy with FOLFIRINOX and preoperative chemoradiotherapy for patients with locally advanced rectal cancer (UNICANCER-PRODIGE 23): A multicentre, randomised, open-label, phase 3 trial. Lancet Oncol 22: 702-715, 2021

10. Li Y, Wang J, Ma XW, Tan L, Yan Y, Xue C, Hui B, Liu R, Ma H and Ren J: A Review of neoadjuvant chemoradiotherapy for locally advanced rectal cancer. Int J Biol Sci 12: 1022-1031, 2016.

11. Cunningham D, Atkin W, Lenz HJ, Lynch HT, Minsky B, Nordlinger B and Starling N: Colorectal cancer. Lancet 375: 1030-1047, 2010.

12. Roh MS, Colangelo LH, O'Connell MJ, Yothers G, Deutsch M, Allegra CJ, Kahlenberg MS, Baez-Diaz L, Ursiny CS, Petrelli NJ and Wolmark N: Preoperative multimodality therapy improves disease-free survival in patients with carcinoma of the rectum: NSABP R-03. J Clin Oncol 27: 5124-5130, 2009.

13. Sun Z, Adam MA, Kim J, Turner MC, Fisher DA, Choudhury KR, Czito BG, Migaly J and Mantyh CR: Association between neoadjuvant chemoradiation and survival for patients with locally advanced rectal cancer. Colorectal Dis 19: 1058-1066, 2017.

14. Park IJ, You YN, Agarwal A, Skibber JM, Rodriguez-Bigas MA, Eng C, Feig BW, Das P, Krishnan S, Crane CH, et al: Neoadjuvant treatment response as an early response indicator for patients with rectal cancer. J Clin Oncol 30: 1770-1776, 2012.

15. Ravenda P, Gregato G, Rotundo M, Frassoni S, Dell'Acqua V, Trovato C, Petz W, Rafaniello Raviele P, Bagnardi V, Bertolini F, et al: Predictive value of circulating tumor-derived DNA (ctDNA) in patients with locally advanced rectal cancer (LARC) treated with neoadjuvant chemoradiotherapy (CT-RT): Preliminary results. Ann Oncol 29: V85, 2018.

16. do Canto LM, Barros-Filho MC, Rainho CA, Marinho D, Kupper BEC, Begnami MDFS, Scapulatempo-Neto C, Havelund BM, Lindebjerg J, Marchi FA, et al: Comprehensive Analysis of DNA methylation and prediction of response to Neoadjuvanttherapy in locally advanced rectal cancer. Cancers (Basel) 12: 3079, 2020.

17. Timudom K, Akaraviputh $\mathrm{T}$, Chinswangwatanakul V, Pongpaibul A, Korpraphong P, Petsuksiri J, Ithimakin S and Trakarnsanga A: Predictive significance of cancer related-inflammatory markers in locally advanced rectal cancer. World J Gastrointest Surg 12: 390-396, 2020.

18. Vuijk FA, van de Water C, Lent-van Vliet $S$, van der Valk MJM, Simmer F, van de Velde CJH, Vahrmeijer AL, Nagtegaal ID and Hilling DE: Intra-Tumoral genomic heterogeneity in recta cancer: Mutational status is dependent on preoperative biopsy depth and location. Cancers (Basel) 13: 2271, 2021.

19. Davnall F, Yip CS, Ljungqvist G, Selmi M, Ng F, Sanghera B, Ganeshan B, Miles KA, Cook GJ and Goh V: Assessment of tumor heterogeneity: An emerging imaging tool for clinical practice? Insights Imaging 3: 573-589, 2012.

20. Greenbaum A, Martin DR, Bocklage T, Lee JH, Ness SA and Rajput A: Tumor heterogeneity as a predictor of response to neoadjuvant chemotherapy in locally advanced rectal cancer. Clin Colorectal Cancer 18: 102-109, 2019.

21. Bundschuh RA, Dinges J, Neumann L, Seyfried M, Zsótér N, Papp L, Rosenberg R, Becker K, Astner ST, Henninger M, et al: Textural parameters of tumor heterogeneity in ${ }^{18} \mathrm{~F}-\mathrm{FDG}$ $\mathrm{PET} / \mathrm{CT}$ for therapy response assessment and prognosis in patients with locally advanced rectal cancer. J Nucl Med 55: 891-897, 2014

22. Lambin P, Rios-Velazquez E, Leijenaar R, Carvalho S, van Stiphout RG, Granton P, Zegers CM, Gillies R, Boellard R, Dekker A and Aerts HJ: Radiomics: Extracting more information from medical images using advanced feature analysis. Eur J Cancer 48: 441-446, 2012.
23. Aerts HJ, Velazquez ER, Leijenaar RT, Parmar C, Grossmann P, Carvalho S, Bussink J, Monshouwer R, Haibe-Kains B, Rietveld D, et al: Decoding tumour phenotype by noninvasive imaging using a quantitative radiomics approach. Nat Commun 5: 4006,2014

24. Gillies RJ, Kinahan PE and Hricak H: Radiomics: Images are more than pictures, they are data. Radiology 278: 563-577, 2016.

25. Kiessling F: The changing face of cancer diagnosis: From computational image analysis to systems biology. Eur Radiol 28: 3160-3164, 2018

26. Lambin P, Leijenaar RTH, Deist TM, Peerlings J, de Jong EEC, van Timmeren J, Sanduleanu S, Larue RTHM, Even AJG, Jochems A, et al: Radiomics: The bridge between medical imaging and personalized medicine. Nat Rev Clin Oncol 14: 749-762, 2017.

27. Bi WL, Hosny A, Schabath MB, Giger ML, Birkbak NJ, Mehrtash A, Allison T, Arnaout O, Abbosh C, Dunn IF, et al: Artificial intelligence in cancer imaging: Clinical challenges and applications. CA Cancer J Clin 69: 127-157, 2019.

28. Larue RT, Defraene G, De Ruysscher D, Lambin P and van Elmpt W: Quantitative radiomics studies for tissue characterization: A review of technology and methodological procedures. Br J Radiol 90: 20160665, 2017.

29. Liang C, Cheng Z, Huang Y, He L, Chen X, Ma Z, Huang X, Liang $C$ and Liu Z: An MRI-based radiomics classifier for preoperative prediction of Ki-67 status in breast cancer. Acad Radiol 25: 1111-1117, 2018.

30. Bulens P, Couwenberg A, Intven M, Debucquoy A, Vandecaveye V, Van Cutsem E, D'Hoore A, Wolthuis A, Mukherjee P, Gevaert O and Haustermans K: Predicting the tumor response to chemoradiotherapy for rectal cancer: Model development and external validation using MRI radiomics. Radiother Oncol 142: 246-252, 2020.

31. Zhang Z, Shen L, Wang Y, Wang J, Zhang H, Xia F, Wan J and Zhang Z: MRI Radiomics signature as a potential biomarker for predicting KRAS status in locally advanced rectal cancer patients. Front Oncol 11: 614052, 2021.

32. Petresc B, Lebovici A, Caraiani C, Feier DS, Graur F and Buruian MM: Pre-treatment T2-WI based radiomics features for prediction of locally advanced rectal cancer non-response to Neoadjuvant chemoradiotherapy: A preliminary study. Cancers (Basel) 12: 1894, 2020.

33. Chen Q, Xia T, Zhang M, Xia N, Liu J and Yang Y: Radiomics in stroke neuroimaging: Techniques, applications, and challenges. Aging Dis 12: 143-154, 2021.

34. Fornacon-Wood I, Faivre-Finn C, O'Connor JPB and Price GJ: Radiomics as a personalized medicine tool in lung cancer: Separating the hope from the hype. Lung Cancer 146: 197-208, 2020.

35. Gardin I, Gregoire V, Gibon D, Kirisli H, Pasquier D, Thariat J and Vera P: Radiomics: Principles and radiotherapy applications. Crit Rev Oncol Hematol 138: 44-50, 2019.

36. Bogowicz M, Vuong D, Huellner MW, Pavic M, Andratschke N, Gabrys HS, Guckenberger M and Tanadini-Lang S: CT radiomics and PET radiomics: Ready for clinical implementation? Q J Nucl Med Mol Imaging 63: 355-370, 2019.

37. Hood L and Friend SH: Predictive, personalized, preventive, participatory (P4) cancer medicine. Nat Rev Clin Oncol 8: 184-187, 2011.

38. Pickhardt PJ: Recent developments in colorectal imaging. Curr Opin Gastroenterol 31: 76-80, 2015.

39. Rutegard MK, Batsman M, Axelsson J, Brynolfsson $P$, Brännström F, Rutegård J, Ljuslinder I, Blomqvist L, Palmqvist R, Rutegård $\mathrm{M}$ and Riklund K: PET/MRI and PET/CT hybrid imaging of rectal cancer-description and initial observations from the RECTOPET (REctal Cancer trial on PET/MRI/CT) study. Cancer Imaging 19: 52, 2019.

40. Raman SP, Chen Y and Fishman EK: Evolution of imaging in rectal cancer: Multimodality imaging with MDCT, MRI, and PET. J Gastrointest Oncol 6: 172-184, 2015.

41. Gal O, Feldman D, Mari A, Baker FA, Hebron D and Kopelman Y: Computerized tomography criteria as a tool for simplifying the assessment of locally advanced rectal cancer. J Gastrointest Cancer 51: 130-134, 2020.

42. Rymer B, Curtis NJ, Siddiqui MR and Chand M: FDG PET/CT can assess the response of locally advanced rectal cancer to Neoadjuvant chemoradiotherapy: Evidence from meta-analysis and systematic review. Clin Nucl Med 41: $371-375,2016$ 
43. Avallone A, Aloj L, Pecori B, Caracò C, De Stefano A, Tatangelo F, Silvestro L, Granata V, Bianco F, Romano C, et al: ${ }^{18}$ F-FDG PET/CT is an early predictor of pathologic tumor response and survival after preoperative radiochemotherapy with bevacizumab in high-risk locally advanced rectal cancer. J Nucl Med 60: 1560-1568, 2019.

44. Schmidt G: Importance of whole body MRI for staging of colorectal cancer. Radiologe 52: 537-544, 2012 (In German).

45. Georgiou PA, Tekkis PP, Constantinides VA, Patel U, Goldin RD, Darzi AW, John Nicholls R and Brown G: Diagnostic accuracy and value of magnetic resonance imaging (MRI) in planning exenterative pelvic surgery for advanced colorectal cancer. Eur J Cancer 49: 72-81, 2013.

46. Jhaveri KS and Hosseini-Nik H: MRI of rectal cancer: An overview and update on recent advances. AJR Am J Roentgenol 205: W42-W55, 2015.

47. Klessen C, Rogalla P and Taupitz M: Local staging of rectal cancer: The current role of MRI. Eur Radiol 17: 379-389, 2007.

48. Attenberger UI, Pilz LR, Morelli JN, Hausmann D, Doyon F, Hofheinz R, Kienle P, Post S, Michaely HJ, Schoenberg SO and Dinter DJ: Multi-parametric MRI of rectal cancer-do quantitative functional MR measurements correlate with radiologic and pathologic tumor stages? Eur J Radiol 83: 1036-1043, 2014.

49. Xu Q, Xu Y, Sun H, Jiang T, Xie S, Ooi BY and Ding Y: MRI evaluation of complete response of locally advanced rectal cancer after Neoadjuvant therapy: Current status and future trends. Cancer Manag Res 13: 4317-4328, 2021.

50. Yi X, Pei Q, Zhang Y, Zhu H, Wang Z, Chen C, Li Q, Long X, Tan F, Zhou Z, et al: MRI-Based radiomics predicts tumor response to neoadjuvant chemoradiotherapy in locally advanced rectal cancer. Front Oncol 9: 552, 2019.

51. Mirbagheri N, Kumar B, Deb S, Poh BR, Dark JG, Leow CC and Teoh WM: Lymph node status as a prognostic indicator after preoperative Neoadjuvant chemoradiotherapy of rectal cancer. Colorectal Dis 16: O339-O346, 2014.

52. Cai C, Hu T, Gong J, Huang D, Liu F, Fu C and Tong T: Multiparametric MRI-based radiomics signature for preoperative estimation of tumor-stroma ratio in rectal cancer. Eur Radiol 31 3326-3335, 2021

53. De Cecco CN, Ganeshan B, Ciolina M, Rengo M, Meinel FG Musio D, De Felice F, Raffetto N, Tombolini V and Laghi A: Texture analysis as imaging biomarker of tumoral response to Neoadjuvant chemoradiotherapy in rectal cancer patients studied with 3-T magnetic resonance. Invest Radiol 50: 239-245, 2015.

54. Cui Y, Yang W, Ren J, Li D, Du X, Zhang J and Yang X: Prognostic value of multiparametric MRI-based radiomics model: Potential role for chemotherapeutic benefits in locally advanced rectal cancer. Radiother Oncol 154: 161-169, 2021.

55. Kapiteijn E, Marijnen CA, Nagtegaal ID, Putter H, Steup WH, Wiggers T, Rutten HJ, Pahlman L, Glimelius B, van Krieken $\mathrm{JH}$, et al: Preoperative radiotherapy combined with total mesorectal excision for resectable rectal cancer. N Engl J Med 345: 638-646, 2001.

56. Chetty R, Gill P, Govender D, Bateman A,Chang HJ, Deshpande V, Driman D, Gomez M, Greywoode G, Jaynes E, et al: International study group on rectal cancer regression grading: Interobserver variability with commonly used regression grading systems. Hum Pathol 43: 1917-1923, 2012.

57. Bahadoer RR, Dijkstra EA, van Etten B, Marijnen CAM, Putter H, Kranenbarg EM, Roodvoets AGH, Nagtegaal ID, Beets-Tan RGH, Blomqvist LK, et al: Short-course radiotherapy followed by chemotherapy before total mesorectal excision (TME) versus preoperative chemoradiotherapy, TME, and optional adjuvant chemotherapy in locally advanced rectal cancer (RAPIDO): A randomised, open-label, phase 3 trial. Lancet Oncol 22: 29-42, 2021.

58. Smith JJ, Strombom P, Chow OS, Roxburgh CS, Lynn P, Eaton A, Widmar M, Ganesh K, Yaeger R, Cercek A, et al: Assessment of a watch-and-wait strategy for rectal cancer in patients with a complete response after Neoadjuvant therapy. JAMA Oncol 5: e185896, 2019

59. Maas M, Nelemans PJ, Valentini V, Das P, Rödel C, Kuo LJ, Calvo FA, García-Aguilar J, Glynne-Jones R, Haustermans K, et al: Long-term outcome in patients with a pathological complete response after chemoradiation for rectal cancer: A pooled analysis of individual patient data. Lancet Oncol 11: 835-844, 2010.

60. Dinapoli N, Barbaro B, Gatta R, Chiloiro G, Casà C, Masciocchi C, Damiani A, Boldrini L, Gambacorta MA, Dezio M, et al: Magnetic resonance, vendor-independent, intensity histogram analysis predicting pathologic complete response after radiochemotherapy of rectal cancer. Int J Radiat Oncol Biol Phys 102: 765-774, 2018.
61. Li Y, Liu W, Pei Q, Zhao L, Güngör C, Zhu H, Song X, Li C, Zhou Z, Xu Y, et al: Predicting pathological complete response by comparing MRI-based radiomics pre- and postneoadjuvant radiotherapy for locally advanced rectal cancer. Cancer Med 8: 7244-7252, 2019.

62. Zhou X, Yi Y, Liu Z, Cao W, Lai B, Sun K, Li L, Zhou Z, Feng Y and Tian J: Radiomics-Based pretherapeutic prediction of non-response to Neoadjuvant therapy in locally advanced rectal cancer. Ann Surg Oncol 26: 1676-1684, 2019.

63. Sun Y, Wu X, Lin H, Lu X, Huang Y and Chi P: Lymph node regression to neoadjuvant chemoradiotherapy in patients with locally advanced rectal cancer: Prognostic implication and a predictive model. J Gastrointest Surg 25: 1019-1028, 2021.

64. Okada K, Sadahiro S, Suzuki T, Tanaka A, Saito G, Kamijo A, Akiba $\mathrm{T}$ and Kawada S: Effects of chemoradiotherapy on lymph nodes in patients with rectal adenocarcinoma: Evaluation of numbers and sizes of retrieved lymph nodes inside and outside the radiation field. Anticancer Res 34: 4195-4200, 2014.

65. Lee SH, Lee JL, Kim CW, Lee HI, Yu CS and Kim JC: Oncologic significance of para-aortic lymph node and inferior mesenteric lymph node metastasis in sigmoid and rectal adenocarcinoma. Eur J Surg Oncol 43: 2076-2083, 2017.

66. Kang J, Hur H, Min BS, Kim NK and Lee KY: Prognostic impact of inferior mesenteric artery lymph node metastasis in colorectal cancer. Ann Surg Oncol 18: 704-710, 2011.

67. Mei SW, Liu Z, Wang Z, Pei W, Wei FZ, Chen JN, Wang ZJ, Shen HY, Li J, Zhao FQ, et al: Impact factors of lymph node retrieval on survival in locally advanced rectal cancer with neoadjuvant therapy. World J Clin Cases 8: 6229-6242, 2020.

68. Sartori CA, Sartori A, Vigna S, Occhipinti R and Baiocchi GL: Urinary and sexual disorders after laparoscopic TME for rectal cancer in males. J Gastrointest Surg 15: 637-643, 2011.

69. Herzog T, Belyaev O, Chromik AM, Weyhe D, Mueller CA, Munding J, Tannapfel A, Uhl W and Seelig MH: TME quality in rectal cancer surgery. Eur J Med Res 15: 292-296, 2010.

70. Veenhof AA, Brosens R, Engel AF, van der Peet DL and Cuesta MA: Risk factors and management of presacral abscess following total mesorectal excision for rectal cancer. Dig Surg 26: 317-321, 2009.

71. Yuval JB, Thompson HM and Garcia-Aguilar J: Organ preservation in rectal cancer. J Gastrointest Surg 24: 1880-1888, 2020.

72. Zhou X, Yi Y, Liu Z, Zhou Z, Lai B, Sun K, Li L, Huang L, Feng Y, Cao W and Tian J: Radiomics-based preoperative prediction of lymph node status following neoadjuvant therapy in locally advanced rectal cancer. Front Oncol 10: 604, 2020

73. Marijnen CA: Organ preservation in rectal cancer: Have all questions been answered? Lancet Oncol 16: e13-e22, 2015.

74. Langman G, Patel A and Bowley DM: Size and distribution of lymph nodes in rectal cancer resection specimens. Dis Colon Rectum 58: 406-414, 2015.

75. Yuan Y, Pu H, Chen GW, Chen XL, Liu YS, Liu H, Wang K and Li H: Diffusion-weighted MR volume and apparent diffusion coefficient for discriminating lymph node metastases and good response after chemoradiation therapy in locally advanced rectal cancer. Eur Radiol 31: 200-211, 2021.

76. Newton AD, Li J, Jeganathan AN, Mahmoud NN, Epstein AJ and Paulson EC: A nomogram to predict lymph node positivity following Neoadjuvant chemoradiation in locally advanced rectal cancer. Dis Colon Rectum 59: 710-717, 2016.

77. Song L and Yin J: Application of texture analysis based on sagittal fat-suppression and oblique axial T2-Weighted magnetic resonance imaging to identify lymph node invasion status of rectal cancer. Front Oncol 10: 1364, 2020.

78. Lievre A, Bachet JB, Boige V, Cayre A, Le Corre D, Buc E, Ychou M, Bouché O, Landi B, Louvet C, et al: KRAS mutations as an independent prognostic factor in patients with advanced colorectal cancer treated with cetuximab. J Clin Oncol 26: 374-379, 2008.

79. Sorich MJ, Wiese MD, Rowland A, Kichenadasse G, McKinnon RA and Karapetis CS: Extended RAS mutations and anti-EGFR monoclonal antibody survival benefit in metastatic colorectal cancer: A meta-analysis of randomized, controlled trials. Ann Oncol 26: 13-21, 2015.

80. George B and Kopetz S: Predictive and prognostic markers in colorectal cancer. Curr Oncol Rep 13: 206-215, 2011.

81. Dai D, Wang Y, Zhu L, Jin H and Wang X: Prognostic value of KRAS mutation status in colorectal cancer patients: A population-based competing risk analysis. Peerj 8: e9149, 2020. 
82. Zhou P, Goffredo P, Ginader T, Thompson D, Hrabe J, Gribovskaja-Rupp I, Kapadia M and Hassan I: Impact of KRAS status on tumor response and survival after Neoadjuvant treatment of locally advanced rectal cancer. J Surg Oncol 123: 278-285, 2021.

83. Gupta AK, Bakanauskas VJ, Cerniglia GJ, Cheng Y, Bernhard EJ, Muschel RJ and McKenna WG: The Ras radiation resistance pathway. Cancer Res 61: 4278-4282, 2001.

84. Toulany M, Dittmann K, Kruger M, Baumann $M$ and Rodemann HP: Radioresistance of K-Ras mutated human tumor cells is mediated through EGFR-dependent activation of PI3K-AKT pathway. Radiother Oncol 76: 143-150, 2005.

85. Peng J, Lin J, Qiu M, Zhao Y, Deng Y, Shao J, Ding P, Zhang H, Wan D, Lu Z and Pan Z: Oncogene mutation profile predicts tumor regression and survival in locally advanced rectal cancer patients treated with preoperative chemoradiotherapy and radical surgery. Tumour Biol 39: 1010428317709638, 2017.

86. Coppede F, Lopomo A, Spisni R and Migliore L: Genetic and epigenetic biomarkers for diagnosis, prognosis and treatment of colorectal cancer. World J Gastroenterol 20: 943-956, 2014.

87. Xu Y, Xu Q, Sun H, Liu T, Shi K and Wang W: Could IVIM and ADC help in predicting the KRAS status in patients with rectal cancer? Eur Radiol 28: 3059-3065, 2018.

88. Yeo DM, Oh SN, Choi MH, Lee SH, Lee MA and Jung SE: Histogram analysis of perfusion parameters from dynamic contrast-enhanced MR imaging with tumor characteristics and therapeutic response in locally advanced rectal cancer. Biomed Resm Int 2018: 3724393, 2018

89. Meng X, Xia W, Xie P, Zhang R, Li W, Wang M, Xiong F, Liu Y, Fan X, Xie Y, et al: Preoperative radiomic signature based on multiparametric magnetic resonance imaging for noninvasive evaluation of biological characteristics in rectal cancer. Eur Radiol 29: 3200-3209, 2019.

90. Xu Y, Xu Q, Ma Y, Duan J, Zhang H, Liu T, Li L, Sun H, Shi K, Xie S and Wang W: Characterizing MRI features of rectal cancers with different KRAS status. BMC Cancer 19: 1111, 2019.

91. Oh JE, Kim MJ, Lee J, Hur BY, Kim B, Kim DY, Baek JY Chang HJ, Park SC, Oh JH, et al: Magnetic resonance-based texture analysis differentiating KRAS mutation status in rectal cancer. Cancer Res Treat 52: 51-59, 2020.

92. Chiloiro G, Rodriguez-Carnero $\mathrm{P}$, Lenkowicz J, Casà C, Masciocchi C, Boldrini L, Cusumano D, Dinapoli N, Meldolesi E, Carano D, et al: Delta radiomics can predict distant metastasis in locally advanced rectal cancer: The challenge to personalize the cure. Front Oncol 10: 595012, 2020.

93. Liu Z, Wang S, Dong D, Wei J, Fang C, Zhou X, Sun K, Li L, $\mathrm{Li}$ B, Wang M and Tian J: The applications of radiomics in precision diagnosis and treatment of oncology: Opportunities and challenges. Theranostics 9: 1303-1322, 2019.

94. Mayerhoefer ME, Szomolanyi P, Jirak D, Materka A and Trattnig S: Effects of MRI acquisition parameter variations and protocol heterogeneity on the results of texture analysis and pattern discrimination: An application-oriented study. Med Phys 36: 1236-1243, 2009.
95. Collewet G, Strzelecki M and Mariette F: Influence of MRI acquisition protocols and image intensity normalization methods on texture classification. Magn Reson Imaging 22: 81-91, 2004.

96. Daye D, Tabari A, Kim H, Chang K, Kamran SC, Hong TS, Kalpathy-Cramer J and Gee MS: Quantitative tumor heterogeneity MRI profiling improves machine learning-based prognostication in patients with metastatic colon cancer. Eur Radiol 31: 5759-5767, 2021.

97. Li ZY, Wang XD, Li M, Liu XJ, Ye Z, Song B, Yuan F, Yuan Y, Xia CC, Zhang X and Li Q: Multi-modal radiomics model to predict treatment response to neoadjuvant chemotherapy for locally advanced rectal cancer. World J Gastroenterol 26: 2388-2402, 2020

98. Giannini V, Mazzetti S, Bertotto I, Chiarenza C, Cauda S, Delmastro E, Bracco C, Di Dia A, Leone F, Medico E, et al: Predicting locally advanced rectal cancer response to neoadjuvant therapy with ${ }^{18} \mathrm{~F}$-FDG PET and MRI radiomics features. Eur J Nucl Med Mol Imaging 46: 878-888, 2019.

99. Cui Y, Yang X, Shi Z, Yang Z, Du X, Zhao Z and Cheng X Radiomics analysis of multiparametric MRI for prediction of pathological complete response to neoadjuvant chemoradiotherapy in locally advanced rectal cancer. Eur Radiol 29: 1211-1220, 2019.

100. Liu X, Yang Q, Zhang C, Sun J, He K, Xie Y, Zhang Y, Fu Y and Zhang $\mathrm{H}$ : Multiregional-Based magnetic resonance imaging radiomics combined with clinical data improves efficacy in predicting lymph node metastasis of rectal cancer. Front Oncol 10: 585767, 2021.

101. Chartrand G, Cheng PM, Vorontsov E, Drozdzal M, Turcotte S, Pal CJ, Kadoury S and Tang A: Deep learning: A primer for radiologists. Radiographics 37: 2113-2131, 2017.

102. Parekh VS and Jacobs MA: Deep learning and radiomics in precision medicine. Expert Rev Precis Med Drug Dev 4: 59-72, 2019.

103. Shi L, Zhang Y, Nie K, Sun X, Niu T, Yue N, Kwong T, Chang P, Chow D, Chen JH and Su MY: Machine learning for prediction of chemoradiation therapy response in rectal cancer using pre-treatment and mid-radiation multi-parametric MRI. Magn Reson Imaging 61: 33-40, 2019.

104.Zhu HT, Zhang XY, Shi YJ, Li XT and Sun YS: A deep learning model to predict the response to neoadjuvant chemoradiotherapy by the pretreatment apparent diffusion coefficient images of locally advanced rectal cancer. Front Oncol 10: 574337,2020

This work is licensed under a Creative Commons Attribution-NonCommercial-NoDerivatives 4.0 International (CC BY-NC-ND 4.0) License. 